\section{Is adrenaline inhalation safe?}

\section{Dear Editor,}

It was with pleasure that I read the review article written by Zhang \& Sanguebsche ${ }^{1}$ about the safety of inhaled adrenaline in children with respiratory diseases. The authors were objective in describing the concentration $(1 / 1,000)$ and volume ( 3 to $5 \mathrm{ml}$ ) of the drug, which also appear in the title of the article. However, the daily doses, and probably the serum concentration, were not uniform, considering that three studies with single inhalations were selected, whereas in another four studies the inhalations were repeated even at short-term intervals. ${ }^{1,2}$ In order to evaluate the side effects, which was the aim of the review, this aspect greatly supports the conclusions.

The concern with the side effects of adrenaline is not new, and it is justified due to the clinical and experimental history of severe effects - extrasystole, ventricular fibrillation and death. ${ }^{3-5}$ This electrocardiographic and clinical sequence may occur in a very short-term period. ${ }^{2}$

By considering these aspects, the evidence shown by Zhang \& Sanguebsche ${ }^{1}$ in their review does not seem enough to sustain the conclusion that inhaled adrenaline is always safe. The authors selected randomized studies to evaluate different side effects. ${ }^{1}$ However, we do fear the occasional occurrence of cardiac arrhythmia and death. ${ }^{5}$ These adverse effects are not frequent, occur regardless of the heart rate, and they had a slim chance of occurring in the sample of only 238 patients evaluated by the authors.

Tachyarrhythmia and death caused by inhaled adrenaline could be proved, albeit in a limited fashion, with another type of bibliographic search - e.g.: isolated cases. Even so, assessing the occurrence of these cases of arrhythmia and death would be quite difficult, due to the limited use of aerosolized adrenaline in the last decades, ${ }^{5}$ to the difficulty in determining the etiopathogenesis of cardiac side effects in patients with acute viral disease, besides the limited publication of iatrogenic cases in the medical literature. The complementary bibliographic search about the severe adverse effects could include the literature that was available prior to the major electronic databases, a period in which the use of adrenaline for the treatment of respiratory diseases was at its height. ${ }^{3,4}$

Also, the fact that the use of adrenaline is regarded as harmless worries me, since this may have remarkable influence over habitual therapeutic practices regarding respiratory diseases. Inhalations may be repeated at short time intervals, a practice that occurs frequently in cases of poor clinical response. As a consequence, serum levels may reach arrhythmogenic levels. ${ }^{2}$ The same result may originate from misprescriptions. I am afraid that the conclusion of the article in favor of the use of adrenaline might contribute to these problems.

Taking the potential risks of inhaled adrenaline into account, I recommended stating that we are still assessing whether this drug is safe or not, in addition to being careful about its clinical indication. Adrenaline is recommended in few clinical situations, such as severe croup. ${ }^{6}$ Its use in bronchiolitis and tracheobronchitis should be limited, considering the benign outcome of these cases.

In conclusion, the review encouraged the reassessment of the use of inhaled adrenaline in respiratory diseases. Widening the analysis of outcomes is necessary, and clinical indication of this drug should be made judiciously.

\section{References}

1. Zhang L, Sanguebsche LS. Segurança de nebulização com 3 a $5 \mathrm{ml}$ de adrenalina (1:1000) em crianças:uma revisão baseada em evidência. J Pediatr (Rio J). 2005;81:193-7.

2. Brock WJ, Rush GM, Trochimowicz HJ. Cardiac sensitization: methodology and interpretation in risk assessment. Regul Toxicol Pharmacol. 2003;38:78-90.

3. Galgiani JV, Proescher F, Dock W, Tainter ML. Local and systemic effects from inhalation of strong solutions of epinephrine. J Am Med Ass. 1939;112:1929-33.

4. Benson RL, Perlman F. Clinical effects of epinephrine by inhalation. J Allergy. 1948;19:129-40.

5. Beasley R, Pearce N, Crane J, Burgess C. Beta-agonists: what is the evidence that their use increases the risk of asthma morbidity and mortality? J Allergy Clin Immunol. 1990:104 Suppl:S18-30.

6. Fernandes IC, Fernandes JC, Cordeiro A, Hsin SH, Bousso A, Ejzenberg $B$, et al. Eficácia e segurança do uso inalatório da adrenalina- $L$ na laringite pós-intubação utilizada em associação com a dexametasona. J Pediatr (Rio J). 2001;77:179-88.

\section{Bernardo Ejzenberg}

Professor, Medical School, Universidade de São Paulo (FMUSP), São Paulo, SP, Brazil. Coordinator of Research and Publications, Pediatric Division, Hospital Universitário, USP, São Paulo, SP, Brazil

\section{Author's reply}

We thank the reader for his interest in and comments about our review article. The answers to the major issues raised in the letter to the editor are given below:

1. This review article was inspired by the fact that the doses of inhaled epinephrine recommended in the Brazilian 
literature for children with laryngotracheobronchitis are usually lower than 3 to $5 \mathrm{ml}$, as suggested by the international literature. The initial aim of this review was to provide evidence regarding the safety of this therapeutic regime. Only two clinical trials evaluated the effects of inhaled epinephrine $(1: 1,000)$ in a total of 45 children with laryngotracheobronchitis. In order to increase the sample size, we also included clinical trials in patients with bronchiolitis, another acute obstructive respiratory disease. Epinephrine therapy was not uniform across clinical trials on bronchiolitis. Such heterogeneity allowed comparing the side effects among children treated with different doses of epinephrine (see Table 1 in the review article). This comparison failed to show higher prevalence of severe adverse effects among children treated with higher doses ( $\geq 3 \mathrm{ml}$ ) of epinephrine, in single or repeated doses. ${ }^{1-5}$ The inclusion of clinical trials with different doses of epinephrine in this review does not affect the validity of the study or its conclusions.

2. Randomized and controlled clinical trials are the most appropriate design to assess the effects (either beneficial or adverse) of the therapy. ${ }^{6}$ We agree with the reader that when the side effects, such as arrhythmia and death associated with inhaled epinephrine, are infrequent, it would be probably necessary to include more than the 238 patients evaluated in this review for the occurrence of severe side effects. Unfortunately, the inclusion of case reports does not solve this limitation because the confirmation of the causal relationship between exposure (epinephrine) and outcome (arrhythmia and death) is very difficult in case reports due to confounding factors. In spite of this, we performed an electronic search in MEDLINE (from January 1949 to July 2004), using the following keywords: (adrenaline $O R$ epinephrine) AND (death $O R$ arrhythmia OR cardiotoxic effects) AND (inhal* OR nebul*). No additional case report or study was found. The manual search of bibliographic references on the topic, published before the advent of the electronic database is probably unproductive due to the difficult access to old publications and the rare publication of iatrogenic cases in the medical literature.

3. Asthmatic children treated with inhaled epinephrine were not included in this review. However, the data obtained from asthmatic patients may provide useful information on the safety of inhaled epinephrine. Despite the availability of beta-2 agonists, inhaled epinephrine is still used in the United States in asthmatic patients. ${ }^{7}$ Between 1975 and 1997, 115 million Primatene Mist (epinephrine) inhalers were sold in the U.S. During that time, only 13 deaths associated with the use of inhaled epinephrine were reported. Nevertheless, concomitant diseases were considered to have caused three deaths, whereas in the remaining 10 deaths, the association between epinephrine and the death outcome was not confirmed, due to confounding factors, such as drug abuse, incorrect use of inhalers and other health problems. Based on the annual report of the American Association of Poison Control Centers, two deaths were associated with the excessive use of inhaled epinephrine between 1994 and 1998.8,9 The data above indicate the infrequency of severe side effects caused by inhaled epinephrine.
4. The reader's concern with the implications of our study for habitual therapeutic practices regarding respiratory diseases is understandable. It should be underscored that current evidence does not suggest the use of inhaled epinephrine in children with acute viral bronchiolitis; therefore, the results of our study apply better to patients with severe laryngotracheobronchitis for whom the use of inhaled epinephrine is necessary. In this case, 3 to $5 \mathrm{ml}$ of inhaled epinephrine $(1: 1,000)$ should be administered according to the international literature, and the evidence presented in this review article sufficiently shows that inhaled epinephrine therapy is safe. In cases of poor clinical response, the doses may be repeated; however, the potential benefits and adverse effects should be analyzed and careful monitoring should be performed, as in any therapy with possible undesirable effects.

\section{References}

1. Waisman $Y$, Klein BL, Boenning DA, Young GM, Chamberlain JM, O'Donnell R, Ochsenschlager DW. Prospective randomized double-blind study comparing L-epinephrine and racemic epinephrine aerosols in the treatment of laryngotracheitis (croup). Pediatrics. 1992;89:302-6.

2. Fitzgerald $D$, Mellis $C$, Johnson $M$, Allen $H$, Cooper $P$, van Asperen P. Nebulized budesonide is effective as nebulized adrenaline in moderately severe croup. Pediatrics. 1996;97: 722-5.

3. Abul-Ainine A, Luyt D. Short term effects of adrenaline in bronchiolitis: a randomized controlled trial. Arch Dis Child. 2002;86:276-9.

4. Wainwright $C$, Altamirano L, Cheney M, Cheney J, Barber S, Price D, et al. A multicenter, randomized, double-blind, controlled trial of nebulized epinephrine in infants with acute bronchiolitis. N Engl J Med. 2003;349:27-35.

5. Menon K, Sutcliffe T, Klassen TP. A randomized trial comparing the efficacy of epinephrine with salbutamol in the treatment of acute bronchiolitis. J Pediatr. 1995;126:1004-7.

6. Greenberg RS. Clinical trial. In: Greenberg RS, Daniels SR, Flanders WD, Eley JW, Boring JR, editors. Medical epidemiology. 3rd ed. New York: Lange Medical Books; 2001. p. 91-111.

7. Dickinson BD, Altman RD, Deitchman SD, Champion HC. Safety of over-the-counter inhalers for asthma. Chest. 2001;118:522-6.

8. Litovitz TL, Felberg L, Soloway RA, Ford M, Geller R. Annual report of the American Association of Poison Control Centers Toxic Exposure Surveillance System. Am J Emerg Med. 1995; 13:551-97.

9. Litovitz TL, Smilkstein M, Felberg L, Klein-Schwartz W, Berlin R, Morgan JL. Annual report of the American Association of Poison Control Centers Toxic Exposure Surveillance System. Am J Emerg Med. 1997;15:447-500.

\section{Linjie Zhang}

PhD. Associate professor, Mother-Infants Department, Fundação Universidade Federal do Rio Grande (FURG), Rio Grande, RS, Brazil.

\section{Lucas Soares Sanguebsche}

Resident, Hospital Universitário, FURG, Rio Grande, RS, Brazil. 